University of Nebraska - Lincoln

DigitalCommons@University of Nebraska - Lincoln

Improvement of PVX/CMV CP expression tool for display of short foreign antigens

\author{
Angela Natilla \\ United States Department of Agriculture \\ Lev G. Nemchinov \\ United States Department of Agriculture
}

Follow this and additional works at: https://digitalcommons.unl.edu/usdaarsfacpub

Part of the Agricultural Science Commons

Natilla, Angela and Nemchinov, Lev G., "Improvement of PVX/CMV CP expression tool for display of short foreign antigens" (2008). Publications from USDA-ARS / UNL Faculty. 370.

https://digitalcommons.unl.edu/usdaarsfacpub/370

This Article is brought to you for free and open access by the U.S. Department of Agriculture: Agricultural Research Service, Lincoln, Nebraska at DigitalCommons@University of Nebraska - Lincoln. It has been accepted for inclusion in Publications from USDA-ARS / UNL Faculty by an authorized administrator of DigitalCommons@University of Nebraska - Lincoln. 


\title{
Improvement of PVX/CMV CP expression tool for display of short foreign antigens
}

\author{
Angela Natilla, Lev G. Nemchinov* \\ Molecular Plant Pathology Laboratory, Plant Sciences Institute, United States Department of Agriculture, Agricultural Research Service, \\ 10300 Baltimore Avenue, Beltsville, MD 20705, USA
}

Received 12 December 2007, and in revised form 14 January 2008

Available online 26 January 2008

\begin{abstract}
We have previously reported that Potato virus $X$-expressed coat protein of Cucumber mosaic virus (CMV) formed virus-like particles (VLPs), which served as carriers for display of different neutralizing epitopes of Newcastle disease virus (NDV). In this work, we further modified the purification protocol of recombinant VLPs carrying short neutralizing epitopes of the NDV proteins and demonstrated that self-contained capsid protein subunits of CMV transiently expressed from heterologous virus packaged into individual virions morphologically resembling and/or indistinguishable from wild type CMV particles. Homogeneity of the final preparation represents an advance over our previous study, where VLPs were found to be of variable size. Chickens immunized with purified VLPs developed antigen-specific response.

Published by Elsevier Inc.
\end{abstract}

Keywords: Plant-derived vaccines; Plant virus-based expression; Newcastle disease virus

Newcastle Disease virus $\left(\mathrm{NDV}^{1}\right)$, a member of avian paramyxoviruses, is an economically important pathogen of poultry causing a fatal and highly contagious viral disease affecting most species of birds. There is no known treatment for the disease. Prevention and control measures include sanitary prophylaxis and vaccination with live and/ or oil emulsion vaccines containing B1 and La Sota strains, which themselves may cause disease, depending on coinfections and environmental conditions [1]. Several epitopes of NDV were reported to have neutralizing activity $[2,3]$.

We reported previously on the development of protein expression tool based on the Potato virus X (PVX) recom-

\footnotetext{
* Corresponding author. Fax: +1 3015045449.

E-mail address: Lev.Nemchinov@ars.usda.gov (L.G. Nemchinov).

${ }^{1}$ Abbreviations used: CMV, Cucumber mosaic virus; VLPs, virus-like particles; NDV, Newcastle disease virus; PVX, Potato virus $X$; CP, coat protein; a, amino acid; HN, hemagglutinin-neuraminidase; TEM, transmission electron microscopy; TVMV, Tobacco vein mottling potyvirus; TGB, triple gene block.
}

binant vector carrying modified coat protein $(\mathrm{CP})$ of Cucumber mosaic virus (CMV) with inserted foreign epitopes $[4,5]$. In this study we continued the improvement of the PVX/CMV CP-based system by modifying the purification protocol of recombinant VLPs displaying antigenic determinants of the NDV proteins: a 17 amino acid (aa) neutralizing epitope of NDV's fusion (F) protein (aa 6581, [3]), an eight aa neutralizing epitope of the NDV hemagglutinin-neuraminidase (HN) protein (aa 346-353 [2]), and the same epitopes fused together in a tandem $\mathrm{F}-\mathrm{HN}$ construct. Using transmission electron microscopy (TEM) we demonstrated that subunits of CMV capsid protein packaged into individual virions morphologically resembling and/or indistinguishable from wild type CMV particles. Homogeneity of the final preparation represents an advance over our previous study, where VLPs were found to be of variable size [4]. Chickens immunized with PVXderived CMV VLPs carrying eight amino acid-long epitope of NDV hemagglutinin-neuraminidase protein (HN) developed antigen-specific response. 


\section{Materials and methods}

\section{Plasmid construction}

Engineering of PVX/CMV vector containing neutralizing epitopes of fusion $(\mathrm{F})$ and $\mathrm{HN}$ proteins of NDV strain La Sota was previously described in details [4]. Briefly, the recombinant CMV CP constructs with incorporated NDV epitopes were first cloned into PCR TOPO II vector (Invitrogen, Carlsbad, CA), following by digestion with EcoRV, gel-purification and subcloning into EcoRV-linerized and dephosphorylated PVX-based vector pP2C2S (obtained from D. Baulcombe, Sainsbury Laboratories, Norwich, England). The correctness of all of the engineered constructs was confirmed by nucleotide sequencing (ABIPRIZM 373A Genetic Analyzer, DNA Sequencing Facility, Center for Biosystems Research, College Park, MD) and sequence data were analyzed using Lasergene software by DNASTAR (Madison, WI).

\section{Purification of $C M V$}

CMV VLPs were purified from 30 to $100 \mathrm{~g}$ of systemically infected leaf tissue by differential centrifugation using the Lot method [6] with some modifications, as described in Natilla et al. [4]. All purifications were performed within 2 weeks post inoculation to maintain recombinant form of the virus. For further purification of VLPs, linear sucrose gradients were prepared by dissolving $25 \%(\mathrm{w} / \mathrm{v})$ sucrose in $0.05 \mathrm{M} \mathrm{Na}$ citrate, $\mathrm{pH}$ 6.5; ultracentrifuge tubes were filled with sucrose and stored at $-80^{\circ} \mathrm{C}$ overnight or longer. The gradient was formed by thawing the solution at $+4{ }^{\circ} \mathrm{C}$ before addition of $1.5 \mathrm{ml}$ of the supernatant obtained at the previous step. Gradients were fractionated by centrifugation at $86,000 \mathrm{~g}$ for $2.5 \mathrm{~h}$ (SW41 rotor) The opalescent bands containing VLPs at or just below the middle of the gradient were collected, diluted with $0.05 \mathrm{M} \mathrm{Na}$ citrate buffer, $\mathrm{pH} 6.5$ and centrifuged for three more hours at $80,000 \mathrm{~g}$ (SW41 rotor). The final pellets were resuspended in sterile water or in $\mathrm{Na}$ citrate $0.05 \mathrm{M} \mathrm{pH} 6.5$ and tested for antigens by Western blot assays with antibodies specific to CMV, HN, and F epitopes [4], and by TEM.

\section{Electron microscopy}

CMV VLPs were visualized by TEM. Carbon-coated grids were incubated for $1 \mathrm{~min}$ with sucrose gradient-purified preparations of VLPs to capture virions, rinsed by washing with $0.5 \mathrm{ml}$ sterile $\mathrm{H}_{2} \mathrm{O}$ over the grid and stained with a $2 \%$ aqueous solution of uranyl acetate. The grids were examined under a JEOL 100-CXII electron microscope at magnifications of 80,000-200,000.

\section{Immunization of chickens with plant-derived VLPS and Western blotting assays}

Purified samples of CMV-HN in concentration of $0.5 \mathrm{mg} / \mathrm{ml}$ were used to immunize Rhode Island Red
Chickens according to the company protocols (Pacific Immunology Corp., http://www.pacificimmunology.com). Affinity purified CMV-HN antibodies company-tested by ELISA for antigen specificity, were further used in our lab in Western blot assays to test their reactivity against NDV antigens. Western blotting was performed as previously described [4]. Escherichia coli-expressed NDV HN protein and BPL (beta-propiolactone)-inactivated NDV strain La Sota served as positive controls to assess the specificity of antibodies elicited against the CMV-HN antigen. Purified preparation of plant virus unrelated to CMV, Tobacco vein mottling potyvirus (TVMV), was used as a negative control. The samples were subjected to denaturing, followed by Western blotting with CMV-HN or CMV-specific antibody.

\section{Results}

Symptoms and stability of the recombinant virus in plants

As reported previously, PVX/CMV CP-WT virus remained stable for at least 7 months after inoculation [4]. Stability of the recombinant viral constructs carrying CMV CP with different antigenic determinants varied from 2 weeks to 1 month with longer epitopes being the least stable and the short HN epitope the most. The recombinants remained stable for the same period of time after the second passage, when the second passage was performed 2 3 dpi from primary transcript-inoculated plants. In all cases, inoculation of Nicotiana benthamiana plants with T7 RNA transcripts led to systemic infection visibly indistinguishable from wild type PVX symptoms 5-7 days postinoculation (not shown). Expression of CMV CP and immunoreactivity of fused NDV epitopes was confirmed by Western blotting with corresponding antibodies to $\mathrm{CMV}, \mathrm{HN}$, and $\mathrm{F}$ epitopes as shown previously in Natilla et al. [4].

\section{Purification of VLPS}

A linear sucrose gradient separation step was added to the recombinant $\mathrm{PVX} / \mathrm{CMV} \mathrm{CP}$ purification procedure to improve the quality of the final preparation and to allow an accurate view of VLP assembly and structure. The modified purification method combined with sucrose-gradient fractionation step and concentrating the VLPs by ultracentrifugation led to high concentrations of VLP in the samples. The yield, as determined by Bradford assay [7] varied from $0.3 \mathrm{mg} / \mathrm{ml}$ up to $1.8 \mathrm{mg} / \mathrm{ml}$, depending on the amount of fresh tissue used for purification (normally 20-200 g of infected leaves).

\section{Visualization of CMV VLPs by transmission electron microscopy}

TEM examination of gradient-purified and concentrated protein showed that PVX-derived WT CMV CP subunits 
or subunits carrying the NDV epitopes $\mathrm{HN}, \mathrm{F}$, and $\mathrm{F} / \mathrm{HN}$ assembled into characteristic virus-like particles undistinguishable from CMV virions (Fig. 1). Unlike the samples of WT CP, which have infrequent and seldom seen PVX virions, chimeric VLP preparations contained more copurified PVX particles.

\section{Animal immune response to plant-derived VLPs}

Animal immunization was performed to test the antigenic capacity of plant-derived VLP. Based on TEM examination, we have chosen purified preparations of PVX/ $\mathrm{CMV}-\mathrm{HN}$ for the immunization experiments since they contained visibly more VLPs. Antibodies, affinity-purified from immunized chickens bound specifically to the CMV-HN antigen, the whole BPL-inactivated NDV strain La Sota and to the E. coli-expressed HN protein in Western blotting assays but not to the purified sample of unrelated plant virus (Fig. 2A). Electrophoretic mobility of the purified NDV virions probed with antibodies specific to CMVHN revealed two protein bands with an apparent molecular weight of about $75 \mathrm{kDa}$ and $63 \mathrm{kDa}$, presumably corresponding to the uncleaved $\mathrm{HN}_{0}$ precursor and cleaved form of $\mathrm{HN}$ (Fig. 2A) [8-10]. On the contrary, probing membranes with antibodies specific only to the CMV carrier, revealed a major band corresponding to the purified VLPs of CMV-HN (Fig. 2B). Taken together, these experiments confirm serological response developed in immu- nized chickens to the CMV carrier as well as to the antigenic $\mathrm{HN}$ peptide displayed on its surface.

\section{Discussion}

A technology based on non-infectious but highly immunogenic virus-like particles is one of the most prominent alternatives to the attenuated live vaccines that carry a significant risk of virulent escape mutants [11]. Not only they can mimic the structural appearance of the genuine pathogen and stimulate pathogen-specific immune response, but they can also serve as adjuvants and vessels for delivery of fused heterologous antigens. Making VLPs of animal and human viruses in plants as well as using plant virus capsids as carriers for delivery of immunogens has emerged as a safe alternative to bacterial, yeast, insect or mammalian cell production systems and represent a novel and inspiring approach to elicit protective responses against a variety of viral and bacterial infections [12,13].

The PVX/CMV CP transient expression system, reported in our preceding study [4], is based on the production of CMV CP from PVX vector followed by assembly of CMV-like particles. In our current work, a more thorough investigation was made with emphasis on the ability of chimeric VLP with inserted foreign epitopes to form symmetrical CMV-shaped particles. Addition of a linear sucrosedensity gradient to the CMV purification procedure significantly improved the uniformity of appearance of purified CMV VLPs as compared to our previous data [4]. We
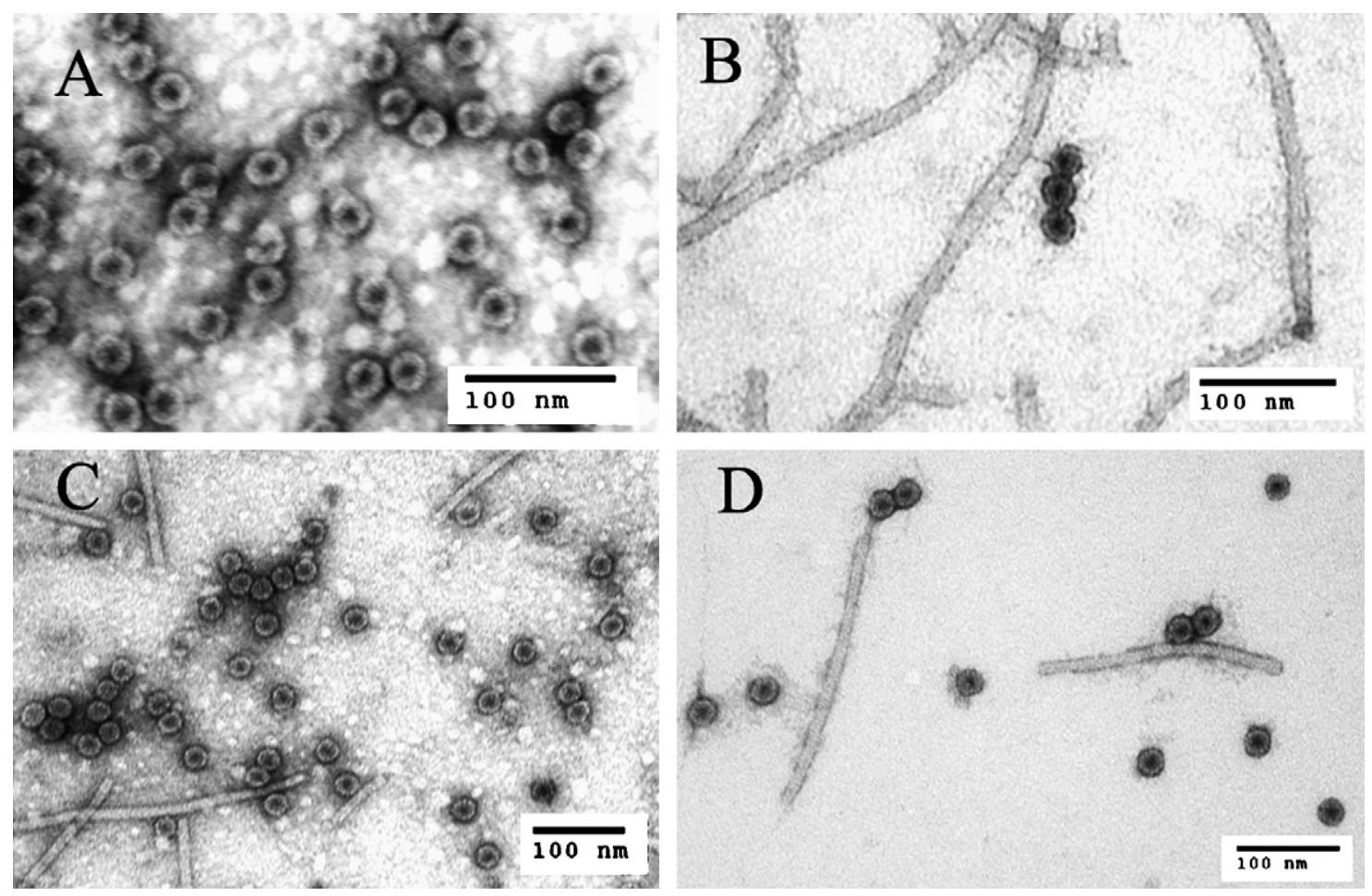

Fig. 1. Transmission electron microscopy of CMV VLPs, purified from Nicotiana bentahamiana plants by standard method [6], fractionated by sucrosedensity gradient and concentrated by high-speed centrifugation. (A) CMV CP-WT; (B) CMV CP-F; (C) CMV CP-HN; (D) CMV CP-F/HN. Bars, $100 \mathrm{~nm}$. 


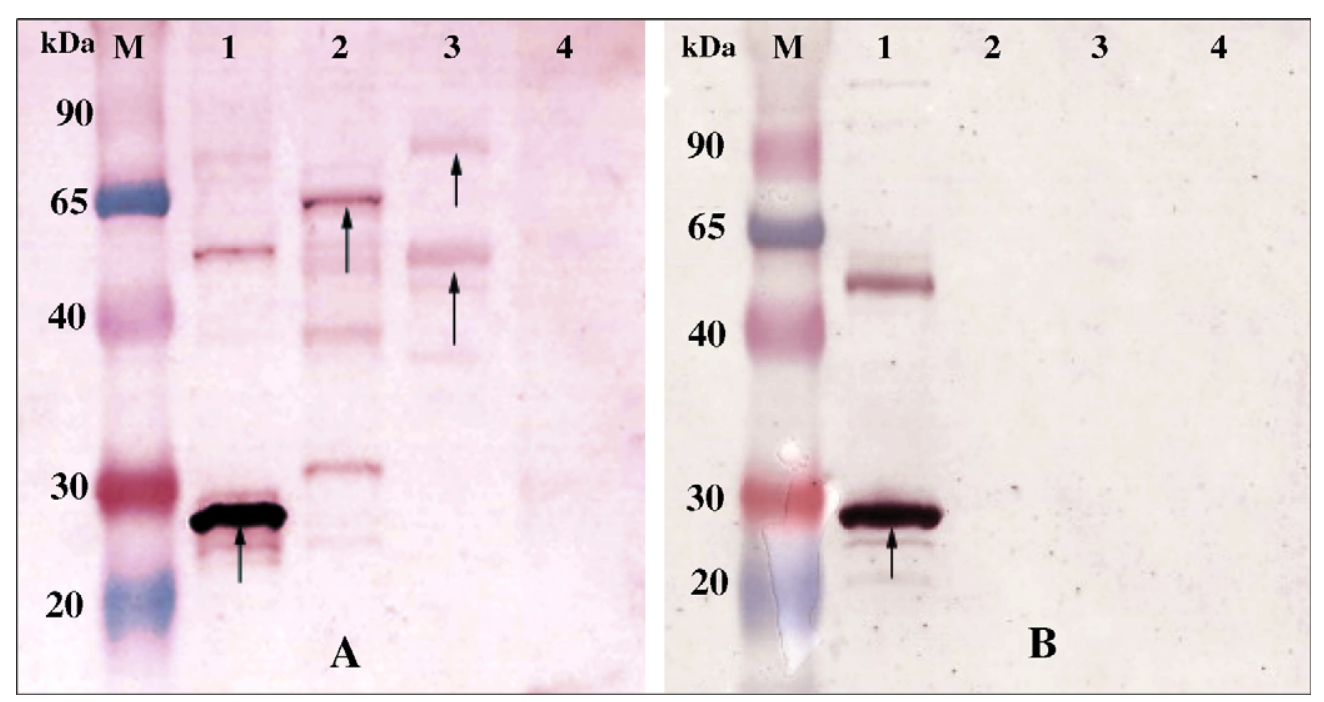

Fig. 2. Western blots, probed with antibodies to CMV-HN antigen (A) or CMV carrier (B). M, ColorBurst molecular weights (kDa) protein marker (Sigma); 1, Purified CMV-HN antigen; 2, E. coli-expressed NDV HN protein; 3, BPL-inactivated NDV strain La Sota; 4, purified preparation of unrelated virus potyvirus as a negative control. Arrows indicate position of the bands specific to the CMV-HN, bacterially expressed HN, and purified NDV La Sota, respectively (A) or the position of CMV-HN antigen (B).

now were able to demonstrate unmistakably that chimeric CMV CP capsids are packaged into typical CMV-like virions. These VLPs are with characteristic structural look and shape of CMV and hence none of the native CMV RNA 3 regions except CP ORF itself is required for assembly of CMV virions. As we demonstrated earlier [4], PVX-derived CMV VLPs may incorporate not only RNA which encodes CMV CP but also a set of PVX subgenomic RNAs downstream from the triple gene block (TGB) including PVX CP RNA. It is evident therefore that if there are any requirements in additional structural elements for CMV to package into the full-sized particles, heterologous PVX subgenomic RNAs may efficiently compensate for them. Gradient-fractionation apparently filtered only uniformsized particles of CMV CP-WT and chimeric CMV CPs. A presence of PVX is not expected to have any influence on the immunogenic properties of the CMV CP-HN antigen since co-purified PVX virions do not contain the antigenic epitopes.

Immunization of chickens with plant-derived CMV VLPs carrying HN peptide elicited antibodies, which specifically recognized purified NDV virions and bacterially expressed HN protein. Apparently, antibody raised against plant-manufactured antigen detected both $\mathrm{HN}_{0}$ precursor protein and cleaved form of $\mathrm{HN}$ and, therefore, are probably not conformationally-sensitive. This may indicate that the $\mathrm{HN}$ epitope presented on CMV particles maintains its linear structure as it was demonstrated for the corresponding antigenic determinant of the $\mathrm{HN}$ glycoprotein [14,15]. Whereas these observations could suggest a possible application of the plant-made protein for prophylactic immunization, the CMV-HN antigen did not protect immunized chickens against experimental challenge with NDV (C. Buanovoglia, A. Natilla, L.G. Nemchinov, unpublished results). Although relevant only to this particular epitope of the virus, this may imply ineffectiveness of a single-epitope approach for the design of plant anti-NDV vaccine. However, diagnostic applications of the non-infectious, plant-derived protein to detect NDV-specific antibodies in serum samples and egg yolk look more feasible.

\section{Acknowledgments}

We are grateful to Charles Murphy of BARC Electron Microscopy Unit for his invaluable help with taking EM images, to Natalia Kovalskaya of Molecular Plant Pathology Laboratory for the gift of bacterially-expressed HN protein and to Jack King of Southeast Poultry Research Laboratory, USDA/ARS, Athens, GA, for BPL-inactivated NDV. We would also like to thank Canio Buanovoglia of Department of Animal Health and Well-being, University of Bari, for sharing his unpublished data on challenge experiments (not presented in the current study).

\section{References}

[1] H. Zhao, H.B.P.H. Peeters, Recombinant Newcastle disease virus as a viral vector: effect of genomic location of foreign gene on gene expression and virus replication, J. Gen Virol. 84 (2003) 781-788.

[2] P. Chambers, M. Nesbit, K. Yusoff, N.S. Millar, A.C. Samson, P.T Emmerson, Location of a neutralizing epitope for the haemagglutinin-neuraminidase glycoprotein of Newcastle Disease Virus, J. Gen Virol. 69 (1988) 2115-2122.

[3] T. Toyoda, B. Gotoh, T. Sakaguchi, H. Kida, Y. Nagai, Identification of amino acids relevant to three antigenic determinants on the fusion protein of Newcastle disease virus that are involved in fusion inhibition and neutralization, J. Virol. 62 (1988) 4427-4430.

[4] A. Natilla, R.W. Hammond, L.G. Nemchinov, Epitope presentation system based on cucumber mosaic virus coat protein expressed from a Potato virus X-based vector, Arch. Virol. 151 (2006) 1373-1386. 
[5] L.G. Nemchinov, A. Natilla, Transient expression of the ectodomain of matrix protein 2 (M2e) of avian influenza A virus in plants, Protein Expr. Purif. 56 (2007) 153-159.

[6] H. Lot, J. Marrou, J.B. Quiot, C. Esvan, A contribution to the study on cucumber mosaic virus (CMV). II. Quick method of purification, Ann. Phytopathol. 4 (1972) 25-38.

[7] M.M. Bradford, A rapid and sensitive method for the quantitation of microgram quantities of protein utilizing the principle of protein-dye binding, Anal. Biochem. 72 (1976) 248-254.

[8] H.-D. Klenk, Y. Nagai, R. Rott, C. Nicolau, The structure and function of paramyxovirus glycoproteins, Med. Microbiol. Immunol. 164 (1977) 35-47.

[9] W. Garten, T. Kohama, H.-D. Klenk, Proteolytic activation of the haemagglutinin-neuraminidase of Newcastle disease virus involves loss of a glycopeptides, J. Gen. Virol. 51 (1980) 207-211.

[10] H.K.A. Ong, A.M. Ali, A.R. Omar, K. Yusoff, Cloning and expression of the $\mathrm{HN}$ gene from the velogenic viscerotropic Newcastle disease virus strain AF2240 in Sf9 insect cells, Cytotechnology 32 (2000) 243-251.
[11] R. Noad, P. Roy, Virus-like particles as immunogens, Trends Microbiol. 11 (2003) 438-444.

[12] S. Biemelt, U. Sonnewald, P. Galmbacher, L. Willmitzer, M. Müller, Production of human papillomavirus Type 16 virus-like particles in transgenic plants, J. Virol. 77 (2003) 9211-9220.

[13] V. Yusibov, S. Rabindran, U. Commandeur, R. Twyman, R. Fischer, The potential of plant virus vectors for vaccine production, Drugs in R\&D 7 (2006) 203-217.

[14] J.G. Alamares, J. Li, R.M. Iorio, Monoclonal antibody routinely used to identify avirulent strains of Newcastle disease virus binds to an epitope at the carboxy terminus of the hemagglutinin-neuraminidase protein and recognizes individual mesogenic and velogenic strains, J. Clin. Microbiol 43 (2005) 4229-4233.

[15] R.M. Iorio, R.J. Syddall, J.P. Sheehan, M.A. Bratt, R.L. Glickman, A.M. Riel, Neutralization map of the hemagglutinin-neuraminidase glycoprotein of Newcastle disease virus: domains recognized by monoclonal antibodies that prevent receptor recognition, J. Virol. 65 (1991) 4999-5006. 